\title{
ARTE E INOVAÇÃO NA TELEVISÃO BRASILEIRA: PRIMEIROS REGISTROS
}

\author{
1João Paulo Hergesel and ${ }^{2}$ Julia Araujo de Lima
}

\author{
Pontifícia Universidade Católica de Campinas, Campinas-São Paulo, Brasil
}

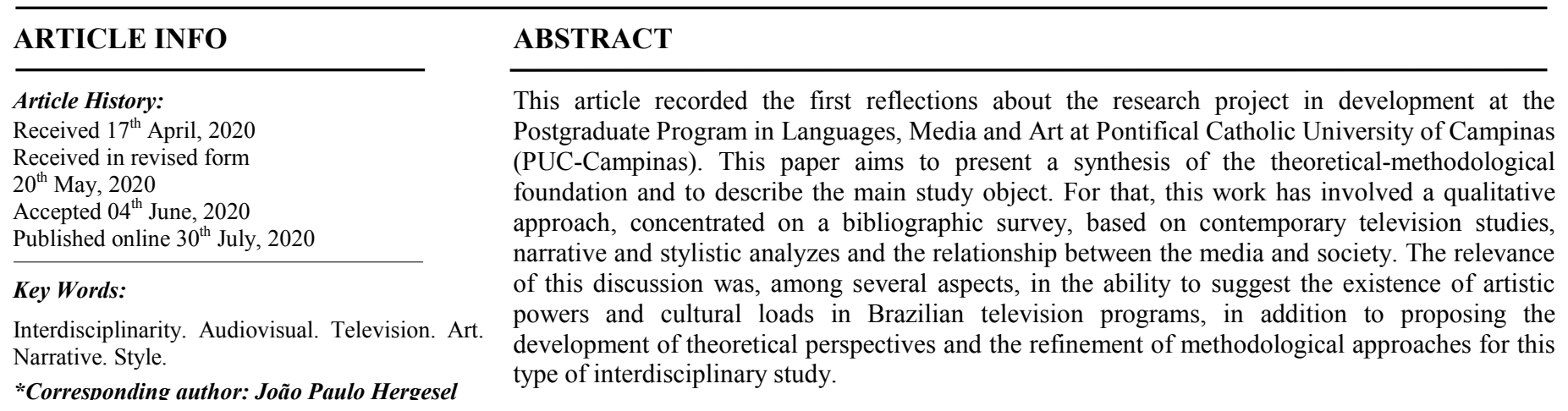

Copyright (C) 2020, João Paulo Hergesel and Julia Araujo de Lima. This is an open access article distributed under the Creative Commons Attribution License, which permits unrestricted use, distribution, and reproduction in any medium, provided the original work is properly cited.

Citation: João Paulo Hergesel and Julia Araujo de Lima, 2020. “Arte e inovação na televisão brasileira: primeiros registros”, International Journal of Development Research, 10, (07), 38254-38257.

\section{INTRODUÇ̃̃o}

Linguagens, Mídia e Arte vêm sendo eixos de pesquisa abordados desde a graduação, especialmente nos trabalhos desenvolvidos pelo primeiro autor deste artigo. Da monografia de conclusão de curso sobre as marcas estilísticas presentes na comunicação verbal escrita de adolescentes nas redes sociais (Hergesel, 2012), transitou-se para a dissertação de mestrado sobre os recursos estilísticos que despontam em webséries brasileiras para o público jovem (Hergesel, 2014), estudo que prosseguiu na tese de doutorado sobre os aspectos narrativos e estilísticos dos quais as produções do Sistema Brasileiro de Televisão (SBT) se apropriam, sobretudo nos programas de auditório e de ficção seriada (Hergesel, 2019a). Ainda consta nesse trajeto a pesquisa de pós-doutorado, que consiste em estudar as relações entre o poético e as narrativas televisivas infantojuvenis, a partir da telenovela As Aventuras de Poliana ${ }^{1}$, adaptação do clássico literário Pollyanna, de Eleanor H. Porter (Hergesel, 2019b). O avanço, proposto pelo projeto do qual este artigo se deriva, está no fato de considerar a mídia televisiva para além das formas convencionais de produção e observá-la em seus aspectos inovadores - discursivos, poéticos e tecnológicos -, sobretudo no que se refere às práticas artísticas manifestadas pela linguagem audiovisual. Parao projeto de pesquisa, o objetivo é compreender como se configuram os discursos, as poéticas e as tecnologias da TV Cultura, a partir do programa Cultura, O Musical (2019), a fim de entender quais são as estratégias de inovação adotadas em suas produções de entretenimento. Dentre os objetivos específicos, estão: a) discutir sobre os fundamentos teóricos, metodológicos e analíticos para a

${ }^{1}$ Disponível em: https://bit.ly/2WT5voq. Acesso em: 25 jul. 2020. pesquisa científica de televisão; b) refletir sobre a criação, as rupturas e as inovações de programas desenvolvidos pela e/ou para a televisão pública no Estado de São Paulo; c) debater as possíveis relações entre arte e mídia, no contexto da televisão brasileira contemporânea; d) estudar processos e produtos que repercutem e causam impactos na sociedade; e) expandir, socializar, popularizar e difundir o conhecimento sobre a mídia televisiva, bem como contribuir com interdisciplinaridade e com internacionalização, a partir da pesquisa proposta. Parte-se do pressuposto de que, ao tornar gratuito o acesso a números musicais, a TV Cultura colabora com a inserção da arte cênica nas mais diversas camadas da população. Com isso, elencamse três hipóteses: 1) por meio da poética televisiva, ocorre a popularização do teatro musical ao redor do Brasil, muitas vezes inacessível por questões espaciais, temporais e financeiras; 2) por meio das tecnologias emergentes, o telespectador convencional é substituído pelo consumidor interagente, que comenta e participa de discussões acerca do que a televisão exibe, não necessariamente na data de exibição original; 3) por meio dos discursos políticos, sociais, históricos, feministas e de diversidade cultural, faz-se a motivação do pensamento crítico do potencial consumidor.

A originalidade da pesquisa, em suma, encontra-se no fato de envolver: a) o enlace entre televisão e arte, fenômeno de pouca observação no cenário nacional; b) a produção da TV pública brasileira, que por vezes é negligenciada pelas pesquisas; c) a cultura da convergência, que requer observações urgentes, em prol do entendimento da sociedade humana; d) análise narrativa e estilística, que ainda estão se consolidando como fundamentação e método para observação de discursos, poéticas e tecnologias em diferentes mídias. A relevância científica, em síntese, está: a) na interdisciplinaridade com as áreas de Comunicação, Letras, Artes e Educação, por propor 
uma discussão sobre linguagens, mídia e arte; b) na capacidade de demonstrar as potências comunicativas e as cargas culturais dos programas televisivos nacionais, por meio das produções de uma TV pública e educativa; c) na expansão dos estudos sobre telepoética, ainda recentes no Brasil; d) no desenvolvimento de perspectivas teóricas e no refinamento de abordagens metodológicas para o estudo das obras televisivas brasileiras, em seus narrativas e estilos. $\mathrm{O}$ impacto para a sociedade, por sua vez, pode ser constatado: a) na compreensão de parte de uma mídia que atinge 97\% dos lares brasileiros, além de ser eleita a mídia preferida por $63 \%$ da população nacional; b) nas discussões sobre o que vem sendo produzido e oferecido para consumo pela televisão pública do Governo do Estado de São Paulo; c) da identificação dos agentes do processo de comunicação televisiva (produtores e consumidores); d) na colaboração com a internacionalização da TV Cultura e, consequentemente, de parcela da arte e da cultura brasileira. Ressaltase, ainda, a pertinência da pesquisa para o Programa de PósGraduação em Linguagens, Mídia e Arte da Pontifícia Universidade Católica de Campinas, com base: a) na inclusão de grupo de estudo sobre televisão e suas relações com outras mídias e práticas artísticas e culturais; b) na possibilidade de oferecimento de seminários temáticos e disciplinas sobre comunicação televisiva e televisualidades; c) na aproximação do tema da pesquisa com os estudos literários e linguísticos, sobretudo nos âmbitos da Narratologia e da Estilística, e com as áreas de cinema e audiovisual. Este artigo, com base no exposto acima, tem como objetivoapresentar uma síntese da fundamentação teórico-metodológica utilizada no projeto, além de descrever o objeto de estudo principal. Para isso, adota-se uma abordagem qualitativa, concentrada no levantamento bibliográfico e embasada nos estudos televisivos contemporâneos, nas análises narrativas e estilísticas e na relação das mídias com a sociedade.

A televisão brasileira e possibilidades de observação: A mídia televisiva exerce forte impacto cultural, social, político e econômico no Brasil, tendo em vista que a televisão continua tendo presença considerável na vida da população. Ela está presente em mais de $97 \%$ dos lares, conforme dados do Instituto Brasileiro de Geografia e Estatística (IBGE) ${ }^{2}$; além disso, é a mídia preferida por $63 \%$ dos brasileiros, conforme estatísticas da Pesquisa Brasileira de Mídia $(\mathrm{PBM})^{3}$. As pesquisas sobre a televisão vêm se fortalecendo no Brasil. Dentre diversos exemplos, corroboram essa afirmação: a longevidade dos grupos de pesquisa da Intercom voltados a essa temática, Fiç̧ão Seriada (coordenado, em 2020, por Ligia Prezia Lemos) ${ }^{4}$ e Estudos de Televisão e Televisualidades (coordenado, em 2020, por Carlos Eduardo Marquioni $)^{5}$; a consolidação do grupo de trabalho Estudos de Televisão da Compós (coordenado, em 2020, por João Martins Ladeira) ${ }^{6}$; e o reconhecimento internacional da Rede de Pesquisadores em Ficção Televisiva Brasileira - Obitel Brasil (coordenado, em 2020, por Maria ImmacolataVassallo de Lopes) ${ }^{7}$.

Em território brasileiro, a televisão teve origem em 1950, com a criação da TV Tupi em São Paulo, de propriedade do empresário Assis Chateubriandt, e por algum tempo se dedicou à transmissão de peças artísticas, como teleteatros e concertos de música clássica (Ribeiro,Sacramento,Roxo, 2010). Com o tempo, porém, visando à ampliação de seu público, a mídia televisiva se rendeu à popularização de seus temas, recorrendo ao melodrama, aos exageros, ao kitsch (Freire Filho, 2008). A narrativa televisiva, embora muito próxima do cinema por utilizar as mesmas modalidades expressivas (Thompson, 2003), tem características ainda mais amplas. Existe um notório hibridismo entre o cênico, o literário, o cinematográfico e o radiofônico; existem matrizes culturais que determinam o desenvolvimento das obras televisivas; e existem fatores que ajudam a determinar a qualidade particular do que se está produzindo/ consumindo na televisão (Capanema, 2017). Para auxiliar na compreensão das narrativas que são criadas na televisão e/ou para a

\footnotetext{
${ }^{2}$ Disponível em: https://bit.ly/2D96REM. Acesso em: 25 jul. 2020.;

${ }^{3}$ Disponível em: https://glo.bo/2OXwhb4. Acesso em: 25 jul. 2020.

${ }^{4}$ Disponível em: https://bit.ly/2D8SwI5. Acesso em: 25 jul. 2020.

${ }^{5}$ Disponível em: https://bit.ly/3jBYoul. Acesso em: 25 jul. 2020.

${ }^{6}$ Disponível em: https://bit.ly/3jHksUg. Acesso em: 25 jul. 2020

7 Disponível em: https://bit.ly/39sI36w. Acesso em: 25 jul. 2020.
}

televisão, há a preocupação com o estilo televisivo, pautado nas escolhas técnicas - movimentação e posicionamento de câmera, conteúdo e disposição da mise-en-scène, trilha sonora, aspectos de edição - de determinado produto (Butler, 2010). Seja em estudos de programas de auditório (Torres, 2004), seja em estudos de ficção seriada (Lopes, 2019), há a necessidade de investir nos debates sobre narrativa e estilo na televisão brasileira. Acredita-se que esse tipo de abordagem permite que "o estudioso pense como um criador, entendendo como os programas são produzidos pela perspectiva dos produtores", além de que "ajuda a desvendar os modos pelos quais um anúncio nos persuade, um noticiário molda perspectivas ou um drama retrata o mundo" (Rocha, 2016, p. 19). Para além disso, a função do estilo em televisão também é "revelar a continuada importância e o valor cultural que a televisão possui em nossas realidades brasileiras" (Rocha, 2016, p. 9). Outra relevância é "contribuir para que o Brasil se reconheça e se aproxime cada vez mais de uma América Latina de língua hispânica cujas matrizes históricas e culturais, conflitos sociais e políticos formam um terreno comum de vivências e compartilhamentos" (Rocha, 2016, p. 11). Soma-se a essa discussão a necessidade de explorar as relações sociais que a televisão brasileira vem exercendo, seja pela ótica dos consumidores (Carrascoza; Rocha, 2011), seja pela cultura de fãs (Lopes, 2015; 2017), seja pela possibilidade de convergência (Jenkins, 2009) e expansão de territórios (Kilpp, 2015). Entretanto, por mais válidas que sejam as contribuições em todos esses campos do conhecimento, o que mais chama a atenção no momento é a relação que a televisão estabelece com a arte.

Relações entre arte e televisão: A arte, para Lotman (1979), é uma forma de conhecimento da vida, um modo de manifestação da poesia em seu sentido amplo, um meio de comunicação pelo qual a linguagem se torna complexa e, consequentemente, requer maior participação do interlocutor para que ocorra a decodificação. Por essa linha de raciocínio, o texto artístico pode ser considerado polissêmico, devido ao seu grau de complexidade, e econômico, por possuir uma grande densidade informacional em (geralmente) um mínimo de matéria. Quando o assunto é a aproximação entre arte e televisão, raros são os especialistas que investigam tal enlace, mesmo considerando que "a demanda comercial e o contexto industrial não inviabilizam necessariamente a criação artística" (Machado,Vélez, 2018 , p. 232). Uma amostra dessa possibilidade é destacada nas peças televisivas de Samuel Beckett, compostas por linguagem desconstruída e formas abstratas (Borges, 2004). Aplicando às produções brasileiras, verificam-se exemplos recentes, como a telenovela Velho Chico (Rede Globo, 2016), que, em detrimento da baixa audiência conquistada, apresenta um trabalho complexo de registro cênico, poético, metafórico, polissêmico, muitas vezes combinado com as artes plásticas (Silva,Camargo, 2018). Salvo as manifestações poéticas presentes na teledramaturgia das grandes emissoras privadas, cabe ressaltar que há televisões públicas que também se esforçam nesse processo, tal qual a TV Cultura, paulista, que, em 2016, foi elevada à categoria de rede nacional pela Anatel ${ }^{8}$.

A tv cultura e o programa cultura, o musical: Em 2020, a TV Cultura completa 60 anos de existência, sendo 50 deles como emissora pertencente ao Governo do Estado de São Paulo. Em outubro de 2019, ainda durante a comemoração de seu quinquagésimo aniversário como rede pública, a TV Cultura Digital, canal da emissora no YouTube ${ }^{9}$, ultrapassou a marca de 1 milhão de inscritos. Além de disponibilizar as atrações exibidas na televisão, como grandes emissoras privadas fazem em suas plataformas de streaming, a TV Cultura ainda cria conteúdo inédito e exclusivo para as redes sociais. Ademais, a inclusão dos vídeos no YouTube permite que seu público interaja entre si por meio de comentários, possibilitando também que a emissora participe dessa interação. A TV Cultura, desde os princípios de sua criação, privilegiou os programas artísticos, com encenações de peças teatrais, adaptações de clássicos da literatura, espetáculos circenses, música erudita, dentre outros fenômenos correlatos (Barros Filho, 2011). Dessa forma, a

\footnotetext{
${ }^{8}$ Disponível em: https://bit.ly/3g1m0Xd. Acesso em: 25 jul. 2020.

${ }^{9}$ Disponível em: https://bit.ly/2OXp6j6. Acesso em: 25 jul. 2020.
} 
emissora criou seus laços sociais a partir de atrações que tinham o compromisso de divulgar a educação, com a cultura e com a ciência (Carmo, 2019), e assim é conhecida, mesmo após seis décadas de existência. Em síntese, a TV Cultura se dedica a uma programação educativa, de caráter muitas vezes artístico e inovador, inclusive em seus programas de entretenimento. Tal circunstância leva a questionar quais estratégias de criação vêm sendo adotadas em seus produtos nacionais e como ocorre a comunhão entre arte e mídia dentro desse contexto.Essa indagação norteia o projeto de pesquisa principal, que traz como corpusprimário o programa Cultura, O Musical (2019).

Descrito pela emissora como "o primeiro reality de musicais do Brasil", Cultura, O Musical contou com 10 programas, além de um making of com excertos das audições, sendo exibido nas manhãs de domingo, entre abril e junho de 2019. O programa contou com mais de 1.200 inscrições, selecionou 36 concorrentes, que disputaram seis eliminatórias e duas semifinais, para definição do "destaque jovem do teatro musical brasileiro". No Brasil, a cultura dos teatros musicais vem crescendo gradativamente. Embora surgido nos espaços cariocas em 1859, sob a égide de "teatro de revista", somente em 1962 houve a primeira montagem inspirada nos musicais norte-americanos, com uma adaptação de My Fair Lady, protagonizada por Bibi Ferreira e Paulo Autran (Cardoso, Fernandes, Cardoso Filho, 2016). O "estilo Broadway" ganhou destaque no Brasil somente nos anos 2000 e contou com a ajuda da televisão para cativar o gosto popular ${ }^{10}$.

Em Cultura, O Musical, trechos de musicais clássicos - como Grease, Hairspray, O Fantasma da Ópera, Chicago, etc. - dividiram espaço com musicais ainda pouco conhecidos no país - como Memphis, Catch Me IfYouCan, ThoroughlyModern Millie, Ragtime, etc. Cada apresentação trouxe sua própria narrativa artística, ressaltada com os componentes estilísticos do audiovisual, para a tela da televisão, além de incluir discursos (políticos, sociais, feministas), seja pelos artistas, seja pelos jurados. Como exemplo, cita-se a encenação de Marília Nunes Cortes ${ }^{11}$, durante a apresentação da canção Astonishing, do musical Little Women. A atriz incluiu o grito "Marielle!", imitando o gesto icônico do movimento em prol da vereadora carioca Marielle Franco, assassinada em 2018. Na versão da música, destaca-se o posicionamento da artista pela personagem interpretada: "Não vou ficar calada, nem ter medo de nada. Como Marielle, serei especial". Outro exemplo é o posicionamento discursivo de José Possi Neto, diretor teatral, durante o julgamento da apresentação de Lorenzo Tarantelli ${ }^{12}$, artista de 10 anos de idade, caçula da competição. O jovem ator havia encenado um trecho do filme $O$ Rei do Show (The Greatest Showman, 2017), no qual descreve seu desejo de enfrentar as barreiras de um mundo amargo e viver um milhão de sonhos.

Em sua fala, o diretor explicita: "Eu acho incrivel o que o Brasil tem conquistado com seus atores mirins [...]. Eu espero que a nova mentalidade da nova politica brasileira não nos abandone como tem ameaçado, porque é por causa de uma luta que há mais de 20 anos se faz dentro do teatro musical [...] que a gente chegou a ter pessoas como esse menino aqui. [...] O Brasil que se espelhe nisso!" Torna-se instigante a possibilidade de percepção dos discursos impregnados nas narrativas que se formam durante as apresentações, que criam rupturas com a padronização do musical estadunidense (muitas vezes em releitura) e exaltam a identidade brasileira, em sua realidade social. Com esse movimento, a TV Cultura torna-se descentralizada do padrão das demais emissoras de televisão, cujas características, na maior parte das vezes, acabam sendo mascarar a diversidade cultural visando a uma hegemonia do audiovisual. Nas palavras de JesúsMartín-Barbero e GermanRey (2004, p. 39), “contraditória modernidade a da televisão em países nos quais a desproporção do espaço social que a mídia ocupa - ao menos, em termos da

\footnotetext{
${ }^{10}$ Uma amostra da popularização dessa arte é o programa Máquina da Fama (SBT, 2013-2017), apresentado por Patrícia Abravanel nas noites de segundafeira - obra que já foi corpus de estudos antecessores (HERGESEL; FERRARAZ, 2017).

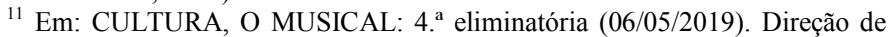
José Roberto Walker. São Paulo: TV Cultura, 2019. telev., color., son.

${ }^{12}$ Em: CULTURA, O MUSICAL: 3. eliminatória (29/04/2019). Direção de José Roberto Walker. São Paulo: TV Cultura, 2019. telev., color., son.
}

importância que adquire o que nela aparece - é, contudo, proporcional à ausência de espaços políticos de expressão e negociação dos conflitos e a não representação, no discurso da cultura oficial, da complexidade e diversidade dos modos de vida e dos modos de sentir das pessoas".

\section{MATERIAL E MÉTODOS}

A televisão, em suma, é uma mídia sujeita a hibridismos e mutações, o que dificulta a criação de uma metodologia fixa para análise. Dentro dessa linha de reflexão, pesquisadores como Arlindo Machado e Marta Lucía Velez (2018) apontam que, até que se consiga alcançar um pressuposto metodológico que cumpra enfaticamente com o intuito de aprofundar as explicações sobre esse fenômeno audiovisual, torna-se necessário o uso do método de tentativas, rascunhos, experimentações. Para que se realize a pesquisa proposta, tem-se optado, num primeiro momento, pelo método qualitativo, de objetivo exploratório, com levantamento de dados, ancorado na revisão de fontes bibliográficas e documentais. Já num segundo momento, pretende-se fazer um esforço analítico, combinando as análises narrativa e estilística, mesclando com os estudos culturais e culminando na proposta de Butler (2010) para a telepoética. Para o estudo das narrativas que se formam nos programas e dos recursos estilísticos impregnados nos objetos de análise, parte-se do entendimento de narrativa como a produção comunicativa e cultural que é guiada por um enredo e movimentada por personagens em uma específica noção de tempo dentro de um espaço, sob um determinado foco narrativo (Barthes et al, 1973). Ou ainda, como o produto cultural que consiste em enunciar a apresentação de um caso, prosseguido por um conflito, acarretando o discorrimento de ações, direcionando-se a um ponto culminante que se desprende na resolução desse emaranhado (Aristóteles, 2005).

Junta-se a isso o estilo, entendido, a partir da leitura de Bordwell (2008) e Butler (2002, 2010), como o conjunto de aspectos expressivos que compõem determinada peça, como os registros de câmera (movimentação, angulação, resolução, etc.), os detalhes da mise-en-scène (enquadramento, cenário, iluminação, encenação, figurino, maquiagem, etc.); e os componentes da trilha sonora (músicas, efeitos, falas, diálogos, etc.). Somam-se também as características peculiares da expressividade, como as figuras de linguagem, como sugere Bally (1905; 1909). O estudo da telepoética, por sua vez, justifica-se na ideia de Butler (2010), de que não se trata de mero formalismo acadêmico, mas de uma forma de abordagem que entende o estilo como a manifestação concreta do tema e da narrativa (as técnicas das quais o audiovisual lança mão para registrar as histórias e os discursos). Além disso, abrange também a situação cultural desses elementos. Para isso, Butler (2010) sugere que as obras sejam analisadas em quatro dimensões: 1) descritiva, responsável pela decupagem do material audiovisual; 2) análise/interpretação, que examina os possíveis efeitos que a obra pode proporcionar; 3) avaliativa, responsável por determinar a qualidade da narrativa televisiva; 4) histórica, que tende a situar o programa em seu contexto presente, por meio de revisitações de influências do passado.

Com a finalidade de entrosamento com essa perspectiva, a pesquisa aqui proposta tende a entender a comunicação televisiva e as práticas culturais da televisão a partir das abordagens propostas por MartínBarbero (2009), em especial quanto aos mapas metodológicos das mediações. Registra-se, portanto, o compromisso do pesquisador em sair da zona de conforto da análise focada no conteúdo para expandir os olhares e abranger também as discussões sociais e culturais do texto televisivo. A seleção das cenas a serem estudadas, por sua vez, tem como norte o método de escolha proposto por Pucci Jr. et al (2013, p. 97): “[...] basta que se analisem os pontos nodais da trama, isto é, aqueles que podem conter os elementos necessários para que se atinja o objetivo da investigação". Desse modo, para o projeto principal, propõe-se um recorte das apresentações dos candidatos de Cultura, O Musical nos episódios correspondentes às eliminatórias, às semifinais e à grande final, priorizando as que contiverem força 
discursiva e/ou que promovam discussões por meio dos recursos tecnológicos. Para realização do trabalho, portanto, planeja-se lançar mão de uma pesquisa: a) bibliográfica, propondo novos levantamentos teóricos sobre os estudos já publicados a respeito do tema (intersecções entre televisão e arte); b) empírica, aplicando testes de caráter qualitativos sobre os objetos que compõem o corpus; c) analítico-conteudista, observando como a narrativa se materializa e quais recursos estilísticos são apropriados pelas obras; d) analíticointegral, servindo da ideia de integração do material para se pensar o produto midiático a partir de um movimento cíclico que inclui os processos discursivos, poéticos e tecnológicos.

\section{RESULTADOS ESPERADOS}

Espera-se, com o desenvolvimento do projeto, contribuir com as discussões científicas acerca do conteúdo da TV Cultura, em especial no contexto contemporâneo; registrar o impacto social que tal emissora (pública e educativa) vem trazendo para o Estado de São Paulo; observar quem são os sujeitos agentes desse processo de comunicação televisiva (produtores e consumidores); e auxiliar na internacionalização da referida emissora, a partir de apresentações em congressos no exterior, publicações em periódicos estrangeiros e debate com os pares de outras nacionalidades. Para isso, almeja-se que os resultados sejam avaliados e disseminados por meio de publicações em periódicos científicos e apresentações em congressos interdisciplinares. Acreditamos que, ao apresentar recortes e papersramificados da pesquisa central em grupos temáticos e ouvir as críticas e aconselhamentos dos pares, possíveis adequações poderão ser feitas, com o propósito de preencher lacunas e enriquecer o trabalho. Cremos, ainda, que, ao submeter artigos e ensaios que colaborem com a temática pesquisada a revistas científicas e receber o parecer da comissão avaliadora, possíveis desvios poderão ser corrigidos, a fim de formular fundamentações e análises mais encorpadas.

Para além dessas estratégias, a disseminação tende a ocorrer de outras três formas: 1) por meio de blog (ou produto similar) voltado ao tema, de acesso livre e periodicamente atualizado com informações pertinentes e resenhas de assuntos diretos e correlatos; 2) com o apoio dos grupos de pesquisa, devidamente certificados pelo Conselho Nacional de Desenvolvimento Científico e Tecnológico (CNPq), ao qual o pesquisador se encontra vinculado; 3 ) com a compilação dos trabalhos realizados em forma de livro digital, também de acesso livre e gratuito, após a conclusão da pesquisa. Procura-se, também, internacionalizar a pesquisa, por meio da publicação em línguas inglesa e espanhola de textos oriundos do trabalho principal, tanto como capítulos de livros organizados por instituições estrangeiras quanto como artigos publicados em periódicos vinculados a IES no exterior. A manutenção da participação na RedInav é outra forma de popularizar a pesquisa em países da América Latina, assim como os diálogos com o OBITEL fortalecem nossa imersão em âmbito iberoamericano. A presença em congressos que apresentam caráter internacional também é uma maneira de fazer com que os resultados sejam apresentados aos pares de outras nacionalidades. Em prol da divulgação científica e da popularização da ciência e da inovação, há a intenção de adotar algumas estratégias para que ramificações da pesquisa cheguem à sociedade geral. Num primeiro momento, estimase a elaboração de textos curtos (resenhas, críticas, ensaios), em linguagem acessível, a serem circulados em jornais de notícias e revistas, bem como parece viável a produção de vídeos, imagens e postagens pensadas para circulação nas redes sociais virtuais. É cogitada, também, a visita a escolas de Ensino Fundamental e Médio, para realização de atividades acadêmico-culturais com crianças e adolescentes. Em suma, ao longo dos anos de pesquisa, espera-se: a) publicar artigos em revistas qualificadas; b) participar de congressos e seminários nacionais e internacionais; c) promover discussões sobre o trabalho em andamento com outros pesquisadores dos grupos de pesquisa de vínculo; d) organizar livro(s) com os resultados da pesquisa; e) criar e publicar site (ou produto similar) com resultados da pesquisa; f) contribuir para novas metodologias de processos e práticas em linguagens, mídia e arte, no âmbito da comunicação televisiva.

\section{REFERÊNCIAS}

Aristóteles (2005). Retórica. 2. ed. Lisboa: Imprensa Nacional, Universidade de Lisboa.

BallyC (1905). Précis de stylistique. Genebra: A. Eggimann.

BallyC (1909). Traité de stylistique française. Paris: Klincksieck.

Barros FilhoEA (2011).Por uma televisão cultural-educativa e pública. São Paulo: Cultura Acadêmica.

BordwellD (2008). Figuras traçadas na luz: a encenação no cinema. Campinas: Papirus.

BorgesG (2004). A poética televisual de Samuel Beckett. Galáxia.8:149-160.

ButlerJG (2010). Television style. Nova Iorque: Routledge.

ButlerJG (2002). Television. 2. ed. Mahwah: Lawrence Erlbaum Associates.

CapanemaLXL (2017). Por uma narratologia da ficção televisual. Tríade.5(9):34-51.

CardosoAB,FernandesAJ,Cardoso FilhoC (2016). Breve história do teatro musical no Brasil e compilação de seus títulos. Música Hodie, 16(1):2944.

CarmoHR (2019). Terra Dois, uma mimese mediada. Dissertação (Mestrado em Linguagens, Mídia e Arte) - Pontifícia Universidade Católica de Campinas, Campinas.

CarrascozaJA, RochaRM(orgs) (2011). Consumo midiático e culturas da convergência. São Paulo: Miró Editorial.

Freire FilhoJ (2008). O debate sobre a qualidade da televisão no Brasil: da trama os discursos à tessitura das práticas. InBorgesG,Reia-BaptistaV (orgs).Discursos e práticas de qualidade na televisão. Lisboa: Livros Horizonte,pp. 78-99.

HergeselJP (2019a). A televisão brasileira em ritmo de festa. Tese (Doutorado em Comunicação) - Universidade Anhembi Morumbi, São Paulo.

HergeselJP (2014). Considerações estilísticas sobre webséries brasileiras. Dissertação (Mestrado em Comunicação e Cultura) -Universidade de Sorocaba, Sorocaba.

HergeselJP (2012).Estilística cibernética e expressividade adolescente. Monografia (Licenciatura em Letras) - Universidade de Sorocaba, Sorocaba.

HergeselJP (2019b). Nuances poéticas nas narrativas midiáticas infantis e juvenis. Anais do XIII Encontro de Pesquisadores em Comunicação e Cultura. Sorocaba: Uniso.

HergeselJP,FerrarazR (2017). A fama da máquina televisiva: análise estilística do programa do SBT. Contracampo. 36:81-99.

HergeselJP,FerrarazR (2018). Estilo SBT de comunicar: análise de programas de auditório. Alumínio: Jogo de Palavras, Votorantim:Provocare.

Jenkins H (2009). Cultura da convergência. São Paulo: Aleph.

KilppS (2003). Quadros de entrevista em programas de auditório: alternativa para análise da TV no Brasil. Revista de Estudos da Comunicação. $4(8): 19-26$.

KilppS (2015). Sentidos identitários de programação em TVs on-line. eCompós. 18(3):1-17.

Lopes MIV (org) (2019). A construção de mundos na fição televisiva brasileira. Porto Alegre: Sulina.

LopesMIV (org) (2015). Por uma teoria de fãs da ficção televisiva brasileira. Porto Alegre: Sulina.

Lopes MIV (org) (2017). Por uma teoria de fãs da ficção televisiva brasileira II: práticas de fãs no ambiente da cultura participativa. Porto Alegre: Sulina.

LotmanI (1979). A estrutura do texto artístico. Lisboa: Estampa.

MachadoA,VelézML (2018). Análise do programa televisivo. São Paulo: Alameda.

Martín-BarberoJ (2009). Dos meios às mediações. Rio de Janeiro: Editora UFRJ.

Martín-BarberoJ,ReyG (2004). Os exercícios do ver. São Paulo: Senac São Paulo.

PucciJuniorRLet al (2013). Avenida Brasil: o lugar da transmidiação entre as estratégias narrativas da telenovela brasileira. InLopesMIV (org) Estratégias de transmidiação na ficção televisiva brasileira. Porto Alegre: Sulina, pp. 75-131.

Ribeiro APG,SacramentoI,RoxoM(org) (2010). História da televisão no Brasil. São Paulo: Contexto.

Rocha SM (2016). Estilo televisivo. Florianópolis: Insular.

SilvaMCC,CamargoBE (2018). Representações da morte nas narrativas midiáticas: a poética da novela Velho Chico. Verso e Reverso. 32(80):133-141.

ThompsonK (2003). Storytelling in Film and Television. Cambridge, Londres: Harvard.

Torres, CLCL (2004). O que o povo vê na TV. Dissertação (Mestrado em Ciências da Comunicação) - Universidade de São Paulo, São Paulo. 